\title{
Vem ser feliz: estratégias de controle e manipulação discursiva das emoções nos domínios publicitário e corporativo ${ }^{1}$
}

\section{Come on be happy: strategies of control and discursive manipulation of emotions in advertising and corporate realms}

Rogério Luiz Covaleski

Leonardo Pinheiro Mozdzenski ${ }^{3}$

Resumo: Este artigo investiga como os domínios publicitário e corporativo buscam controlar e manipular discursivamente as afetividades e subjetividades de consumidores e trabalhadores, atrelando-as aos valores organizacionais, com o fim de melhorar a eficiência produtiva, incrementar o consumo e maximizar seus lucros. Metodologicamente, procedeu-se à análise de publicidades e cases empresariais que evidenciam o papel das emoções no neoliberalismo, com base das proposições de Casaqui (2017), Castro (2013), Charaudeau (2016), Deleuze (1992), Elias (1994), Freire Filho (2010), Foucault (2004), Illouz (2011), Lazzarato (2004), entre outros. Como resultado da pesquisa, constata-se que atualmente as emoções são concebidas como um capital da empresa, assumindo a missão de vincular afetivamente consumidores e trabalhadores à alma da corporação.

Palavras-chave: emoção; controle; manipulação discursiva; publicidade.

1 Uma versão deste trabalho foi anteriormente apresentada ao GT “Consumos e Processos de Comunicação” do XXVII Encontro Anual da Compós, PUC-MG, Belo Horizonte, em junho de 2018.

2 Universidade Federal de Pernambuco (UFPE). Recife, PE, Brasil. https://orcid.org/0000-0002-9537-6961.E-mail: rogerio@covaleski.com.br.

3 Universidade Federal de Pernambuco (UFPE). Recife, PE, Brasil. https://orcid.org/0000-0002-4010-5507.E-mail: leo_moz@yahoo.com.br. 
Abstract: This article investigates how advertising and corporate domains seek to control and manipulate discursively the affectivities and subjectivities of consumers and workers, linking them to organizational values, in order to improve productive efficiency, increase consumption and maximize profits. Methodologically, we analyzed advertisings and entrepreneurship cases that highlight the role of emotions in neoliberalism, based in Casaqui (2017), Castro (2013), Charaudeau (2016), Deleuze (1992), Elias (1994), Freire Filho (2010), Foucault (2004), Illouz (2011), Lazzarato (2004), among others. As a result of the research, we verified that today emotions are conceived as a company's capital, assuming the mission of affectively linking consumers and workers to the soul of the corporation.

Keywords: emotion; control; discursive manipulation; advertising. 


\section{Introdução: a felicidade do consumidor e a gestão emocional do trabalhador}

Amor, diversão, alegria, satisfação, sucesso, excitação, bem-estar. Paixões, emoções e afetos desempenham um papel fundamental para a publicidade, constituindo estratégias poderosas das quais o criativo frequentemente lança mão para chamar atenção de um público cada vez mais anestesiado pela superexposição multimidiática. Nesse contexto, ressalta Casaqui (2011), a publicidade promove a materialização do sentimento de felicidade via consumo: sonhos e desejos abstratos são presentificados pelo discurso publicitário e consubstanciados sob a forma de marcas e mercadorias. Castro (2013) salienta ainda que, mais do que vender produtos ou serviços, as empresas anseiam hoje pelo engajamento afetivo dos consumidores. Vaz (2010) pondera que nas culturas ocidentais contemporâneas, o direito à felicidade é o lema maior do indivíduo.

Essa felicidade à qual teríamos direito e seria nosso dever perseguir é apresentada como residindo na esfera privada e estaria relacionada ao consumo de bens e serviços. Graças ao onipresente discurso publicitário, basta pensar em ser feliz que surgem em nossa mente imagens de uma família sorrindo numa casa repleta de objetos que trariam conforto e aliviariam a dureza do trabalho doméstico (VAZ, 2010, p. 135).

É o que se observa, por exemplo, a partir de famosos slogans de campanhas brasileiras que tematizam a felicidade do consumidor, tais como Lugar de gente feliz, do Pão de Açúcar, Seja você. Seja feliz, da Riachuelo, e Vem ser feliz, do Magazine Luiza (Figura 1). 
Figura 1 - A "felicidade" nos slogans publicitários do Pão de Açúcar, da Riachuelo e do Magazine Luiza
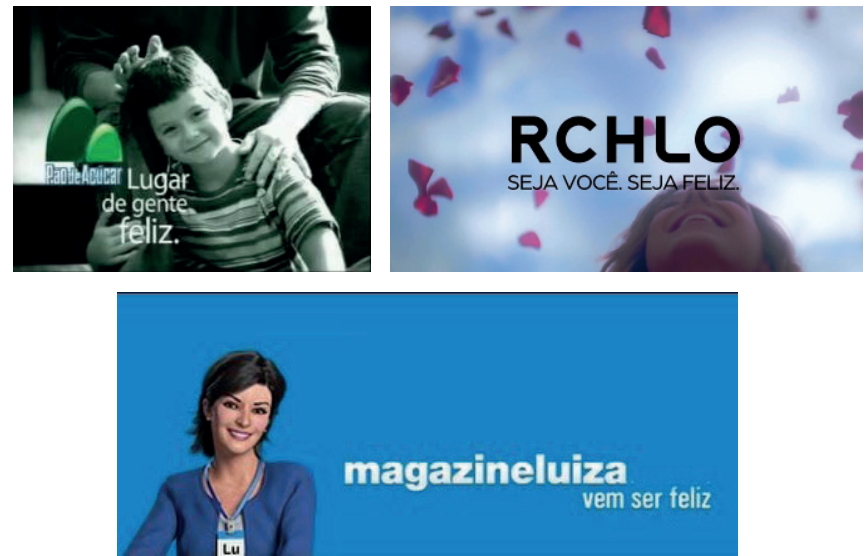

Fonte: YouTube (Disponíveis em: http://bit.ly/2rXhm7O, http://bit.ly/2nGFPJx e http://bit. ly/2DV3fSg, respectivamente. Acesso em: 2 fev. 2018)

Paradoxalmente, não é incomum constatarmos que essa retórica afetiva da felicidade nas peças publicitárias se revela bem distante da realidade das corporações. É o caso das empresas nos três anúncios acima, flagradas exercendo práticas trabalhistas ilícitas. Em 2013, por exemplo, o Grupo Pão de Açúcar foi intimado pela Justiça do Trabalho de Ribeirão Preto para que deixasse de submeter jovens aprendizes a desvios de função (exploração do trabalho infantojuvenil). ${ }^{4} \mathrm{E}$ em 2010, a rede de supermercados foi condenada pela Justiça do Trabalho de São José do Rio Preto a pagar R 100 mil por danos morais coletivos ao manter funcionários em jornadas de trabalho extenuantes. ${ }^{5}$

Já em 2017, o Ministério Público do Trabalho no Rio Grande do Norte moveu uma ação civil pública contra a Riachuelo, solicitando uma indenização coletiva no valor de $\mathrm{R} \$ 37,7$ milhões, em virtude de irregularidades nas confecções que prestam serviços terceirizados ao grupo varejista de moda. Os fiscais inspecionaram mais de 50 confecções, em 12 municípios potiguares, e constataram que os funcionários

4 Disponível em: http://bit.ly/2DXFrNk.

5 Disponível em: http://bit.ly/2DXwsfg. 
terceirizados recebiam remuneração mais baixa e possuíam menos direitos trabalhistas do que os empregados contratados diretamente pela Guararapes Confecções, controladora da Riachuelo. ${ }^{6}$

Por fim, em 2013, o Tribunal Regional do Trabalho de Campinas condenou o Magazine Luiza ao pagamento de $\mathrm{R}$ \$ 1,5 milhão por redução dos custos a partir da eliminação de direitos trabalhistas: os funcionários eram submetidos a jornadas laborais com horas extras excessivas e os intervalos legalmente previstos eram desrespeitados. ${ }^{7}$ Mesmo condenada, a varejista continuou sujeitando seus empregados a expedientes debilitantes, o que levou o Ministério Público do Trabalho a ingressar no judiciário trabalhista, em 2017, com um pedido de multa de $\mathrm{R} \$ 5$ milhões. O procurador Gustavo Rizzo Ricardo comentou o caso:

O Magazine Luiza se autodeclara uma das melhores empresas para se trabalhar no Brasil. Entretanto, os documentos juntados demonstram que a realidade é bem diferente. Jornadas exaustivas, de até 14 horas, deixam claro que a empresa desrespeita reiteradamente a legislação trabalhista. Mesmo após a decisão judicial condenatória, a empresa se recusa a regularizar sua conduta, o que demonstra seu desrespeito com seus trabalhadores e mesmo para com as decisões judiciais. Dessa forma se faz necessária a execução da multa de caráter pedagógico-punitivo para que, por fim, altere sua forma de agir (citado no site do MPT/Campinas). ${ }^{8}$

Essas são apenas algumas das ocorrências em que se evidencia a discrepância entre o posicionamento marcário afetivo fabricado pela publicidade e as práticas neoliberais predatórias adotadas pelas empresas. O neoliberalismo considera a concorrência como a característica definidora das relações humanas. A ideologia neoliberal ressignifica os cidadãos como consumidores que detêm o poder de exercer suas escolhas democráticas por meio da compra e venda - um processo que recompensa o mérito e pune a ineficiência (BOURDIEU, 1998).

Os indivíduos são divididos entre vencedores e fracassados, uma vez que cada um ganha o que merece. Segundo os princípios neoliberais,

6 Disponível em: http://bit.ly/2DXTfM9.

7 Disponível em: http://bit.ly/2nwMhDh.

8 Disponível em: http://bit.ly/2s0wdP3. 
o mercado oferece benefícios que nunca poderiam ser alcançados com a interferência antinatural de agentes externos, sobretudo com a interveniência estatal ou sindical. E quaisquer tentativas de limitar a concorrência são consideradas, portanto, hostis à liberdade.

Contudo, com o propósito de se livrarem da pecha de arrivistas e gananciosas, as empresas vêm gradualmente recorrendo a artifícios gerenciais e discursivos visando mascarar ou romantizar práticas neoliberais abusivas. Gurus corporativos criam, assim, movimentos heteróclitos como o "capitalismo consciente", proposto por John Mackey, CEO da rede norte-americana de supermercados Whole Foods Market (MACKEY; SISODIA, 2013). O empresário advoga que esse movimento se posiciona "contrário à ideia - muito comum no mundo dos negócios - de que todo empresário é explorador e egoísta" e acredita que "erguer uma empresa pode ser um ato bom - muitas vezes até heroico" (MACKEY, 2018, p. 89).

Como tática para reforçar essa imagem mais humanizada e supostamente preocupada em elevar o moral e a qualidade de vida dos seus funcionários - mas sempre perseguindo, na verdade, o crescimento da produtividade e a maior eficiência da força de trabalho -, as corporações vêm recorrendo a psicólogos, pesquisadores comportamentais, palestrantes motivacionais, profissionais de coaching e toda sorte de "empreendedores de palco". Casaqui (2017, p. 14) avalia criticamente essas narrativas inspiracionais que publicizam o ideário da "sociedade empreendedora":

o empreendedorismo se transformou na panaceia, na cura dos males de nosso tempo: do desemprego à infelicidade, passando pela crise de valores, tudo é passível de solução, mediante a prática da atividade empreendedora que combina plano de negócios, psicologia positiva, inspiração.

Em linha semelhante de raciocínio sobre a imperativa busca pela felicidade no ambiente corporativo, Freire Filho (2010, p. 50) entende que "a psicologia positiva, a neurociência e os guias leigos de autoajuda se encarregam de instrumentalizá-la, de redefini-la como um potente 
fertilizante orgânico, uma espécie de aditivo energético natural”. O pesquisador reproduz, ainda, a lógica explicitada em uma importante publicação a respeito da "felicidade à toda prova" [Você S/A, 11 maio 2009]: "Felicidade é um combustível importante para quem pretende crescer na carreira. [...] A sensação de fazer o que gosta e de estar bem consigo mesma permite que a pessoa produza mais, destaque-se e, assim, se habilite para ocupar uma posição mais alta”.

O médico psiquiatra e escritor paulista Augusto Cury é um dos grandes representantes dessa tendência de se empreender com felicidade, ganhando notoriedade nacional com seus livros e conferências sobre "gestão da emoção" e "coaching emocional" para gerenciar a ansiedade e melhorar o desempenho profissional (CURY, 2015). Dessa maneira, rompendo as barreiras entre os universos financeiro e emocional, estratégias de controle e manipulação do afeto no espaço organizacional estão sendo pensadas e incorporadas aos fundamentos da ação econômica, de uma forma radicalmente nova de conceber o processo de produção (ILLOUZ, 2011).

Concomitantemente, a imbricação entre economia e emoção também vem assumindo relevância sob o ponto de vista do consumo. Trata-se da "comercialização do amor" (COSTA, 2005), ou melhor, de um contínuo processo de infiltração, via discurso publicitário, de estímulos comerciais nas afetividades do consumidor e a associação entre símbolos e mercadorias nas relações amorosas. Como aponta Carrascoza (2014, p. 55), "a publicidade é justamente o mediador entre a produção industrial, desumanizada, e o consumo, humanizado, fazendo a nomeação, a individuação dos produtos, para o consumidor”.

Para França (2010, p. 218), “a sociedade atual não pode nos fornecer a 'chave da felicidade' - porque essa sociedade almeja uma chave que abra muitas portas”. Para a autora, esses apelos são veiculados incessantemente por diferentes produtos midiáticos, sobretudo pela publicidade e pelas obras de ficção, que nos lembram da obrigação e dos caminhos para sermos felizes. Bauman (2014, p. 67) também reflete a respeito dessa "chave para felicidade" proporcionada pelas mensagens publicitárias: 
Às vezes as mensagens são claramente explícitas, e outras vezes estão ocultas sutilmente; mas, cada vez mais, apelam às faculdades intelectuais, às emoções ou aos desejos subconscientes, prometem, sugerem e expressam uma felicidade (ou sensações prazerosas, momentos de júbilo, arrebatamento ou êxtase: uma porção de felicidade para toda a vida entregue pouco a pouco, em doses diárias ou por horas e por pouco dinheiro) que forma parte da aquisição, da possessão e do desfrute dos produtos proporcionados em uma loja. A mensagem não pode ser mais clara: o caminho da felicidade passa por ir às compras. (Tradução nossa)

Sendo assim, bens ou serviços podem ser convertidos em uma commodity afetiva e se tornarem um item "queridinho" ou "amado". Com isso em vista, as empresas se empenham para mensurar e controlar o que sente e move o consumidor. "Coerente com os preceitos neoliberais vigentes, investe-se de modo intensivo e constante no engajamento afetivo do consumidor", afirma Castro (2013, p. 177). Ainda segundo a autora, "trabalha-se para que ele [consumidor] seja simultaneamente interpelado e constituído como admirador, endossante e, eventualmente, parceiro e porta-voz da marca junto a seus pares" (CASTRO, 2013, p. 177).

Diante do exposto, é possível argumentarmos que, seja no campo do consumo ou da produção, as afetividades e subjetividades vêm sendo ativamente mobilizadas, moldadas e controladas pelas forças econômicas neoliberais, fazendo com que os sujeitos se tornem, na contemporaneidade, simultaneamente atores emocionais e econômicos. Nesse sentido, a inovação trazida pelo chamado capitalismo emocional é justamente compreender os sentimentos de consumidores e trabalhadores - agentes tradicionalmente situados em etapas distintas do processo produtivo como igualmente fundamentais ao capital afetivo das empresas.

Neste artigo, defendemos que esse fenômeno pode ser mais bem articulado e compreendido a partir de questões geradoras acerca dos mecanismos de controle, vigilância e manipulação das emoções nos domínios publicitário e corporativo. Como se deu a evolução histórica do controle social das emoções tal como concebemos hoje em dia? De que modo o advento do capitalismo emocional contribui para mudança na 
percepção corporativa sobre o papel dos sentimentos de consumidores e trabalhadores? E como isso pode ser observado na prática, em exemplos concretos?

Para fundamentarmos a discussão, partimos primeiramente de Elias (1994a, 1994b), Foucault (1983) e Deleuze (1992), e realizamos um sucinto relato das formas como o controle social dos sentimentos vem sendo tratado desde o final da Idade Média - período considerado o marco inicial da vigilância afetiva na contemporaneidade. Em seguida, a pesquisa irá se voltar especificamente para a compreensão das estratégias de controle afetivo utilizadas atualmente tanto na publicidade quanto nas organizações, e que visam mensurar, dirigir, regular ou mesmo prognosticar os sentimentos de consumidores e dos funcionários da empresa (ILLOUZ, 2011; ANDRADE, 2015). Posteriormente, serão explicitadas as principais técnicas de manipulação discursiva das emoções elencadas por Charaudeau (2016), concebidas originalmente para análise do discurso político, mas que estão sendo aqui retomadas e reconfiguradas para os nossos propósitos.

Ao longo do artigo, apresentaremos peças e cases de publicidade, bem como notícias e informações do mundo publicitário e corporativo, a fim de exemplificar e deslindar as discussões teóricas. Finalmente, no intuito de pôr em ação o modelo de análise elaborado por Charaudeau (2016), elegemos como objeto o "discurso do endomarketing" - isto é, voltado para o marketing interno das empresas -, uma vez que contempla o controle e a manipulação das emoções tanto no discurso publicitário (das agências que divulgam seus serviços de consultoria para melhoria do clima organizacional) quanto no discurso empresarial (das organizações que querem que seus empregados se engajem na missão e nos valores da companhia). Enfim, selecionamos para estudo o filme publicitário Endomarketing, da agência Angelcom, por ser o de maior número de visualizações na plataforma de vídeos YouTube dentre os de conteúdo similar. ${ }^{9}$

9 Disponível em: http://bit.ly/2dZiNuE. 


\section{Um breve relato histórico sobre o controle social das emoções}

Em muitas organizações subjaz um preceito cristalizado no neoliberalismo mais tradicional, mas ainda bem difundido no atual imaginário organizacional: o dever da adoção de uma postura racional e objetiva de autocontrole dos sentimentos no ambiente de trabalho. Nessa visão convencional, o componente emocional estaria adstrito à etapa final do processo produtivo, quando a publicidade desempenharia o seu papel de encantar e seduzir afetivamente os consumidores, persuadindo-os a adquirir o bem ou serviço ofertado. Mas isso nem sempre foi assim.

No clássico O Processo Civilizador, Elias (1994a e 1994b) analisa os efeitos da formação do Estado Moderno sobre os costumes e a personalidade dos indivíduos. O autor se propõe a destrinchar a extensa trama histórica das profundas transformações ocorridas na sociedade desde a Idade Média até a contemporaneidade, em direção à "civilização". Um dos pontos centrais do trabalho é discutir em que medida essas transformações sociopolíticas influenciaram a construção dos afetos e do modo como eles eram socialmente partilhados até se chegar à concepção moderna do controle de emoções individuais por imposição externa e pelo autocontrole.

A tese sustentada pelo sociólogo alemão é que a criação dos Estados Nacionais na Europa exerceu, ao longo do tempo, um papel decisivo no comportamento, nos sentimentos e nas estruturas de controle da sociedade ocidental.

Essa regulação contínua, uniforme e estável de paixões e afetos passará a ser desde então constitutiva da sociedade. É nesse sentido que, segundo Foucault (1983), nos séculos XVII e XVIII, surge a "sociedade disciplinar" como forma de dominação, introjetada nas instituições sociais e afetando as ações, os hábitos e os sentimentos humanos. Na sociedade moderna, industrial e capitalista, a economia do poder conclui que vigiar era mais eficaz e rentável que punir. Nas sociedades disciplinares, o controle do espaço, do tempo e dos movimentos é submetido 
então à "vigilância panóptica" sobre corpos docilizados e confinados nas prisões, escolas, hospitais, quartéis, fábricas (BRUNO, 2013, p. 60).

Já no século XX, com o fim da Segunda Guerra Mundial, emergem forças na sociedade que fundam uma nova ordem, identificadas com mudanças no mundo capitalista, sobretudo no que diz respeito às inovações tecnológicas. O uso dessas novas tecnologias para o controle social se transforma na mais decisiva manifestação do exercício do poder na sociedade atual. É o que Deleuze (1992) identifica como "sociedades de controle". No lugar da disciplina e confinamento, a modulação das sociedades de controle é caracterizada pela invisibilidade e pelo nomadismo que se expande junto às redes de informação. $\mathrm{O}$ controle desenvolve estratégias cada vez menos visíveis e materiais, e cada vez mais sutis, virtuais, dispersas, fluidas, imateriais (HARDT, 2000).

Deleuze (1992, p. 223) ainda faz uma provocação ao afirmar que atualmente se considera que "empresas têm uma alma, o que é efetivamente a notícia mais terrificante do mundo. O marketing é agora o instrumento de controle social, e forma a raça impudente de nossos senhores". De fato, como lembra Lazzarato (2004), o capitalismo contemporâneo não objetiva apenas produzir bens ou serviços. Antes, almeja criar mundos, subjetividades, afetividades. A empresa não fabrica mais mercadorias, mas o mundo onde a mercadoria existe; não produz mais consumidores e trabalhadores, mas sujeitos que habitam nesse mundo livre, lúdico e criativo por ela construído.

Um ótimo exemplo de como a publicidade constrói mundos afetivos pode ser visto na campanha da Sadia veiculada em 2017, intitulada Há 73 anos cada dia + Sadia. ${ }^{10}$ A peça consiste em uma compilação de um minuto de comerciais históricos da marca, veiculados entre 1969 e 2016, com forte apelo sentimental, percebido já no clássico jingle, com vozes de crianças: "É bom saber que alguém te ama de verdade / Bom saber que alguém te quer tão bem / Por toda vida, dentro do peito / É muito bom saber que existe amor assim”. Como revela Cecilia Mondino, diretoria de marcas da BRF (controladora da Sadia):

10 Disponível em: http://bit.ly/2BXw4f6. 
O consumidor tem uma relação emocional com a Sadia, pois a história da marca se confunde com a história das pessoas. Percebemos em pesquisas que a marca ou os próprios produtos são capazes de resgatar memórias, estimular lembranças e marcar momentos na vida do consumidor. Por isso, investimos em uma campanha que valoriza essa conexão e a relação de parceria construída ao longo desses anos (apud LEAL, 2017).

Mais de vinte anúncios com imagens e bordões inesquecíveis compõem o filme, tais como a cena do menino identificando o presunto Sadia em um teste cego, ou dos garotos cantando "Peru de Natal", ou da senhora que reclamava "Nem a pau, Juvenal!" (Figura 2).

Figura 2 - Cenas do comercial Há 73 anos cada dia + Sadia

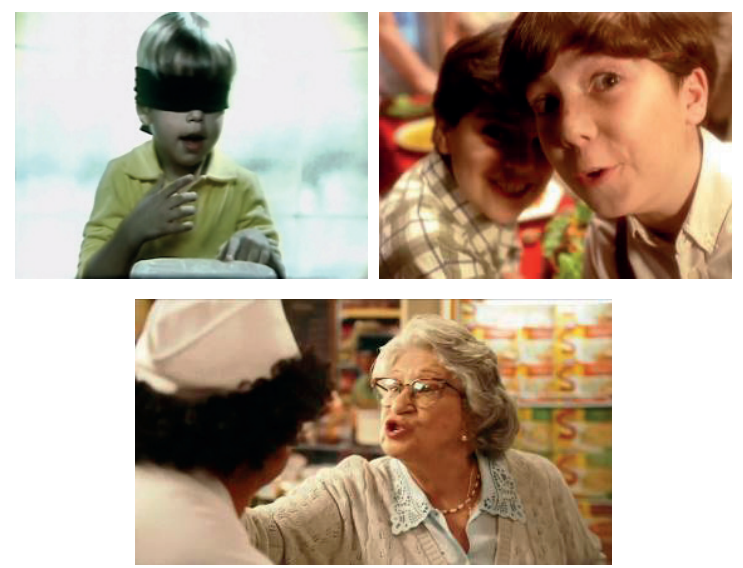

Fonte: YouTube (Disponível em: http://bit.ly/2BXw4f6. Acesso em: 4 fev. 2018)

Para motivar um maior engajamento afetivo do público, foi criado ainda um hotsite ${ }^{11}$ para que as pessoas compartilhassem as suas memórias sobre a Sadia e esses anúncios icônicos. Entre os testemunhos, podemos ler vários depoimentos que narram histórias pessoais e familiares se imbricando com a vida profissional - sua ou a de parentes - dentro da própria Sadia. Em outros momentos, vemos fotos que descrevem lembranças dos funcionários: "como estava feliz no meu primeiro dia

11 Disponível em: https:/www.sadia.com.br/nasuahistoria/home. 
de trabalho", "não era só trabalho, era uma vida, uma família!" e "é emocionante fazer parte dessa história” (Figura 3).

Figura 3 - Imagens/depoimentos do hotsite "Na Sua História", da Sadia
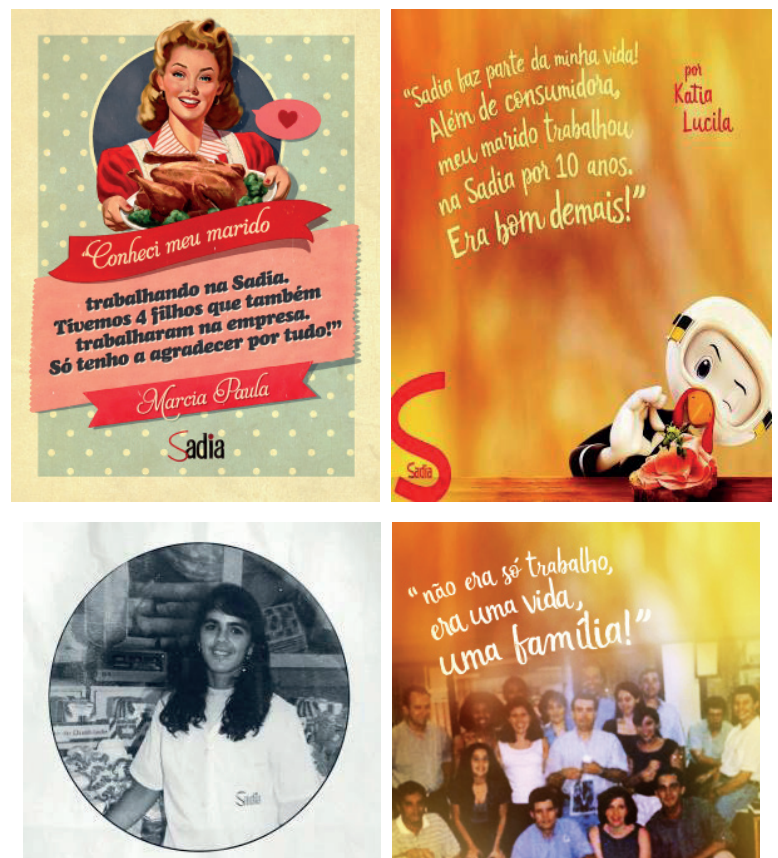

COMECEI A TRABALHAR WA SADIA EM 1991. OLHA COMO ESTAVA FEUZ NO MEU PRIMEIRO DIA DE TRABALHO, DIRETO DO TÚNEL DO TEMPO!
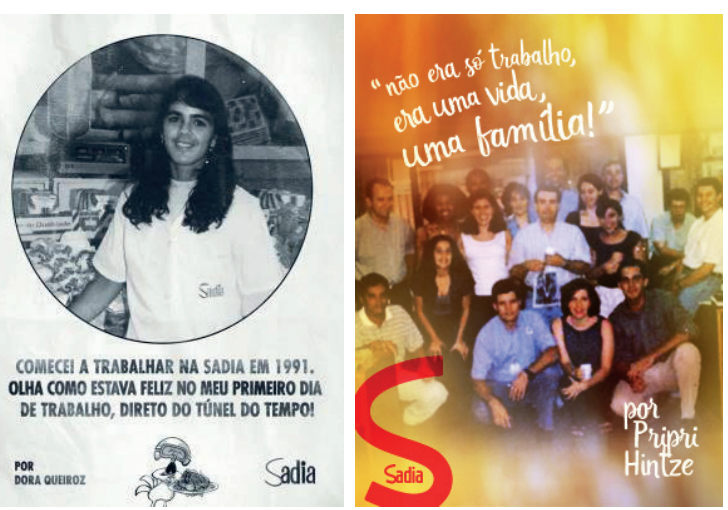

Fonte: Sadia (Disponível em: http://bit.ly/2Ed5iEr. Acesso em: 4 fev. 2018) 
Figura 3 - Imagens/depoimentos do hotsite "Na Sua História”, da Sadia
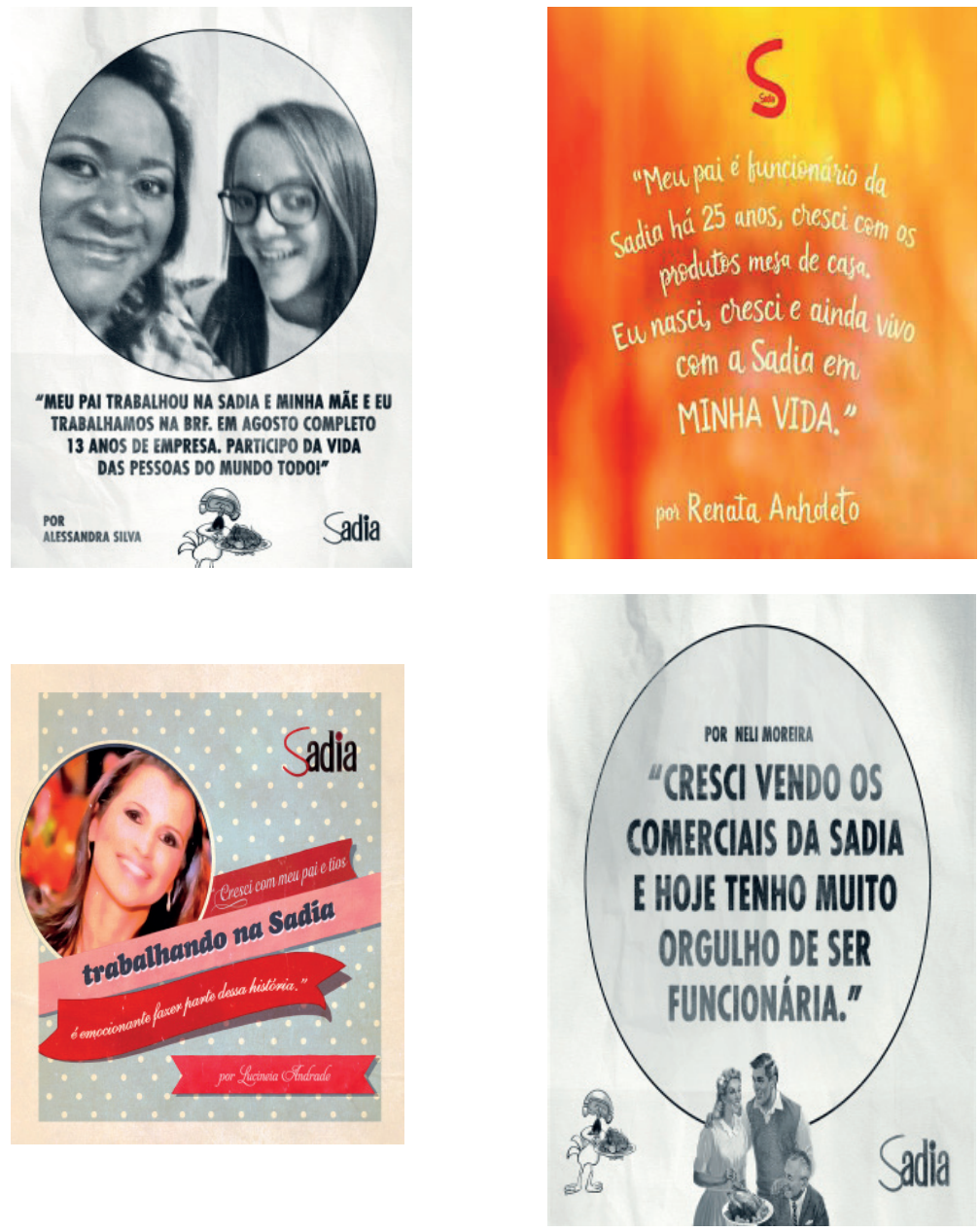

Fonte: Sadia (Disponível em: http://bit.ly/2Ed5iEr. Acesso em: 4 fev. 2018)

Esses relatos deixam evidente, portanto, a exploração publicitária dos aspectos afetivos de seus atores, em que consumidores e trabalhadores partilham de um mesmo sentimento em relação à marca. Daí esse "novo" capitalismo ser chamado de capitalismo emocional:

A noção de capital emocional surgiu como um campo específico de capital humano a receber investimentos. As emoções passaram a ser 
vistas como elementos determinantes da motivação dos trabalhadores, da tomada de decisões, da resistência aos riscos e às mudanças das organizações flexíveis, da persistência na busca de metas, da cooperação e da coordenação dos processos produtivos, da fidelização dos clientes e dos desvios tidos como irracionais no comportamento organizacional. [...] As emoções emergem, assim, como um capital da empresa inseparável das qualidades incorporadas nos trabalhadores e nos consumidores (ANDRADE, 2015, p. 730).

Veremos a seguir que esse discurso do "novo" capitalismo não passa, na verdade, de um conjunto de táticas remodeladas de controle emocional de consumidores e trabalhadores.

\section{O controle do afeto nos domínios publicitário e corporativo}

Ao discutir sobre a fabricação desse mundo afetivo criado pelo capitalismo contemporâneo, Lazzarato (2004, p. 96-97) ressalta que

[...] esse mundo é constituído por arranjos de enunciação, por regimes de signos cuja expressão é chamada de publicidade e cuja manifestação constitui uma solicitação, uma ordem, que são, em si mesmas, uma avaliação, um julgamento, uma crença a respeito do mundo, de si próprio e dos outros. O que é expresso não é uma avaliação ideológica, mas uma incitação [...], uma solicitação a adotar uma forma de vida, isto é, adotar um jeito de se vestir, um jeito de ter um corpo, um jeito de comer, um jeito de comunicar, um jeito de viver, um jeito de se mover, um jeito de ter um estilo, um jeito de falar, etc.

Nesse sentido, cabe à mídia e, em especial, à publicidade a missão de operar como um "locus pedagógico", instruindo o público sobre como se comportar a fim de obter sucesso no seu dia a dia e se adequar à conduta social vigente (FISCHER, 2012; DOMINGUES, 2016). A publicidade surge, pois, como um dos domínios que mais se desenvolveram na atualidade com o propósito de ditar novos hábitos, valores e crenças, bem como nos ensinar de que modo as pessoas devem se comportar, o que devem consumir, como devem se sentir: [...] a publicidade, mais do que 
uma ferramenta do campo do marketing, que visa à persuasão dos consumidores para gerar vendas de produtos e serviços, é uma ferramenta de controle social (DOMINGUES, 2016, p. 15).

A busca pela compreensão do papel exercido pelas emoções e sentimentos na publicidade não é algo exatamente novo. Desde a década de 1920, pesquisadores procuram desvendar esse fenômeno, sobretudo sob um prisma mensuralista. Em outras palavras, a maioria das pesquisas nesse âmbito apresenta como meta principal encontrar, por meio de recursos tecnológicos cada vez mais sofisticados, modos de precisar quantitativamente a resposta emocional do público diante de um anúncio publicitário e, consequentemente, a imagem afetiva da marca ( $c f$. POELS; DeWITTE, 2006). E essa avidez por decifrar, monitorar e direcionar a forma como as pessoas se relacionam sensitivamente com as marcas só vem aumentando ainda mais com o advento da internet e das mídias digitais, onde os internautas são superestimulados a expor abertamente suas opiniões, crenças, simpatias e antipatias.

Essa subjetividade exacerbada, responsável por borrar as fronteiras entre os domínios do público e do privado, vem chamando a atenção de estudiosos das ciências humanas e sociais, que já advogam uma virada afetiva nessas áreas do conhecimento (CLOUGH, 2007). Sustenta-se o reconhecimento da afetividade como um dos elementos centrais para a compreensão da subjetividade e das interações entre os indivíduos na contemporaneidade. O universo da publicidade - sempre atento a tendências comportamentais em função de suas estratégias mercadológicas - não poderia ignorar esse fenômeno.

Especificamente nos domínios publicitário e corporativo, o interesse pelo assunto vendo sendo tratado em geral dentro da lógica do fetichismo da emoção. Sentimentos são objetificados, mensurados e comodificados, isto é, dispostos como mercadorias a serem consumidas. Empresas, agências de publicidade e institutos de pesquisa perseguem incansavelmente o método aferidor mais preciso, capaz de ler e interpretar as afetividades de maneira mais objetiva e com resultados (financeiros) mais produtivos. Com isso, intenta-se valorizar o "principal ativo de uma empresa", que 
é sua marca - tanto a partir do olhar do consumidor (“cliente externo") quanto sob o prisma de quem trabalha na companhia (que passa a ser denominado no atual jargão corporativo de "cliente interno") (THOMSON, 1998).

Por outro lado, há os que criticam a tecnicidade e a realidade simulada das emoções no universo corporativo. É o caso da socióloga Eva Illouz (2011), em sua obra O amor nos tempos do capitalismo, na qual defende que o mundo empresarial vem se tornando um sistema de produção e gestão de sentimentos. Isso se manifesta, segundo a pesquisadora, não apenas no infatigável esforço para decodificar e prognosticar as reações emocionais do público consumidor diante de uma marca ou publicidade, mas também no que diz respeito ao controle do comportamento emocional dos próprios funcionários.

O diferencial é que, na atualidade, esse controle não é mais fundado na vigilância panóptica discutida por Foucault (1983). As estratégias agora são bem mais sutis e efetivas. É o que também afirma Andrade (2015, p. 738):

As técnicas adotadas pela cultura organizacional e pela economia de experiências procuram despertar o êxtase individual e/ou coletivo com a finalidade de vincular afetivamente trabalhadores e consumidores à empresa, obtendo seu engajamento subjetivo. As regras emocionais e expressivas promovidas são as das chamadas "emoções positivas", o trabalhador devendo se sentir e se mostrar motivado, comprometido, entusiasmado, otimista e autoconfiante, desenvolvendo, na relação com seus colegas e clientes, sentimentos morais como simpatia, empatia, lealdade, confiança, responsabilidade, solidariedade e espírito de equipe, mesmo quando as condições de possibilidade desses sentimentos estejam minadas pela precarização do trabalho, pela efemeridade das relações flexíveis, pela competição acirrada e pela ameaça de desemprego. Os trabalhadores, ao contrário do que ocorria no fordismo, não podem mais manifestar desgosto pelo seu trabalho e pelos seus companheiros, correndo o risco de serem tomados como desmotivados e não cooperativos, um pecado mortal no mercado de trabalho atual. 
Para Illouz (2011), o capitalismo só passou a dar importância à vida afetiva dos funcionários com o fim de obter melhores resultados na produção e, por consequência, maiores lucros: "a linguagem da afetividade e da eficiência produtiva foram se entrelaçando cada vez mais, uma moldando a outra" (ILLOUZ, 2011, p. 25).

Esse processo é historicamente explicado por Andrade (2015) a partir do que o autor denomina de genealogia da concepção antropológica do homem econômico emocional, atrelada ao conceito de capital emocional. Segundo o sociólogo, ao se analisar o discurso do management e da economia neoliberal sobre o capital emocional, é possível averiguar uma coerência inédita na construção da vida emocional de trabalhadores e consumidores, sendo parte constituinte da história das maneiras de sentir nas sociedades contemporâneas.

Como esclarece o estudioso, a partir dos anos 1990, especialistas do universo empresarial começaram a salientar o papel das emoções como fator crucial na concorrência entre empresas, defendendo, inclusive, que as competências emocionais são determinantes para estabelecer o êxito ou o fracasso de uma carreira profissional. Com isso, empresários, gestores, consultores e pesquisadores desse campo passaram a tentar compreender melhor o que são as emoções e como elas podem ser (auto)geridas para se atingir resultados mais eficientes e impulsionar os rendimentos financeiros.

Desse modo, "a concepção de homem econômico emocional incide sobre a gestão de trabalhadores; os dispositivos de poder do management constroem a vida emocional dos indivíduos atrelando-a a objetivos corporativos" (ANDRADE, 2015, p. 727). A lógica mercadológica da governabilidade neoliberal, fundada na competição entre empresas e a maximização de proventos, passa a ser internalizada pelos indivíduos. Estes se tornam, assim, um "empreendedor de si mesmo" (FOUCAULT, 2004 , p. 232), assumindo valores empresariais, como o controle, o desempenho, a racionalidade, a competitividade (entre seus pares) etc.

Nesse cenário, os sentimentos se transformam em fatores decisivos para motivar os empregados de uma empresa, dos quais se espera que 
sintam orgulho e satisfação ao "vestir a camisa" da organização. Eles devem se identificar, pois, como parte do "time" ou da "família" naquela corporação, cooperando para satisfazer e fidelizar os clientes. Ao serem apreendidas como estratégias cognitivamente mediadas que, direta e indiretamente, produzem ganhos financeiros e geram contentamento, as emoções convertem-se em objeto de gestão. Conforme Andrade (2015, p. 730), as "emoções emergem, assim, como um capital da empresa inseparável das qualidades incorporadas nos trabalhadores e nos consumidores".

Para atestarmos a relevância dessa discussão, é interessante notarmos justamente aquelas circunstâncias em que se dá uma disrupção, ou seja, quando esse aspecto afetivo fugiu ao controle das empresas e que medidas foram tomadas para solucionar os problemas decorrentes. Uma primeira situação pode ocorrer quando um escândalo ocorre na corporação, tal como envolvimento com corrupção ou descumprimento dos padrões de qualidade, maculando o sentimento do público de confiança e de respeito à ética e à segurança perante a marca. Foi o que ocorreu recentemente com a Petrobras e a JBS. Em ambos os casos, a solução encontrada foi produzir campanhas publicitárias nas quais os próprios funcionários cedem sua voz/imagem à empresa e atuam como fiadores da credibilidade marcária (Figura 4).

Por outro lado, funcionários que não seguem a cartilha de valores da empresa podem ser penalizados com demissão. Dois casos recentes ganharam repercussão na mídia. Em 2017, a filial brasileira da Salesforce, companhia norte-americana de software, demitiu seu presidente Mauricio Prado e mais dois empregados após polêmica envolvendo uma festa à fantasia na empresa, onde um dos funcionários estava fantasiado do meme racista "Negão do WhatsApp" (Figura 5, à esquerda). ${ }^{12}$ Em contrapartida, também em 2017, um gerente premiado do Banco Itaú foi demitido por postar um vídeo nas redes sociais beijando o noivo. ${ }^{13} \mathrm{O}$ contrassenso aqui é que o Itaú adota externamente um discurso

12 Disponível em: http://bit.ly/2E00V0e.

13 Disponível em: http://bit.ly/2GL2zR4. 
pró-diversidade sexual (Figura 5, à direita), o que parece indicar que nem sempre o que se prega é o que se pratica.

Devido a essa importância assumida pela gestão das afetividades na empresa, frequentemente são concebidas novas ferramentas de controle e vigilância das emoções dos empregados. Uma dessas principais ferramentas gerenciais consiste no endomarketing, cujo objetivo - sob o ponto de vista crítico - é manipular os sentimentos dos trabalhadores visando-se ao aumento da produtividade e dos dividendos da empresa. Como isso se dá será o tema a ser discutido a seguir.

Figura 4 - Publicidades Seguindo em frente, da Petrobras, e Qualidade é prioridade, da JBS
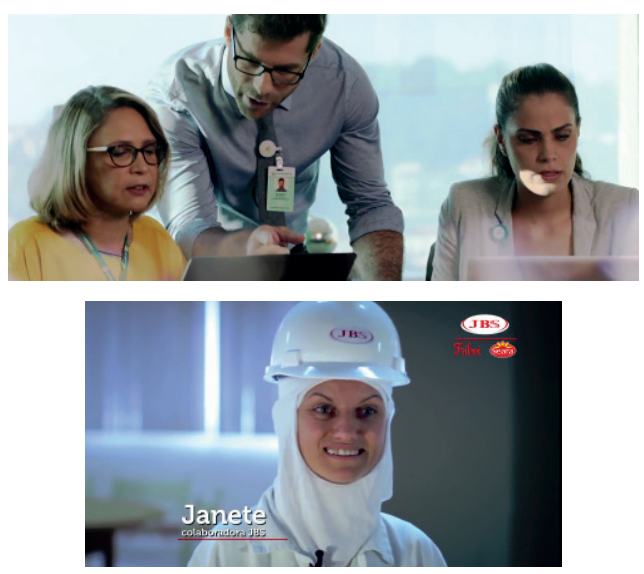

Fonte: YouTube (Disponíveis em: http://bit.ly/2E03oUk e http://bit.ly/2GLlwTS, respectivamente. Acesso em: 4 fev. 2018) 
Figura 5- Funcionários demitidos por descumprirem os valores da empresa: Salesforce e Banco Itaú

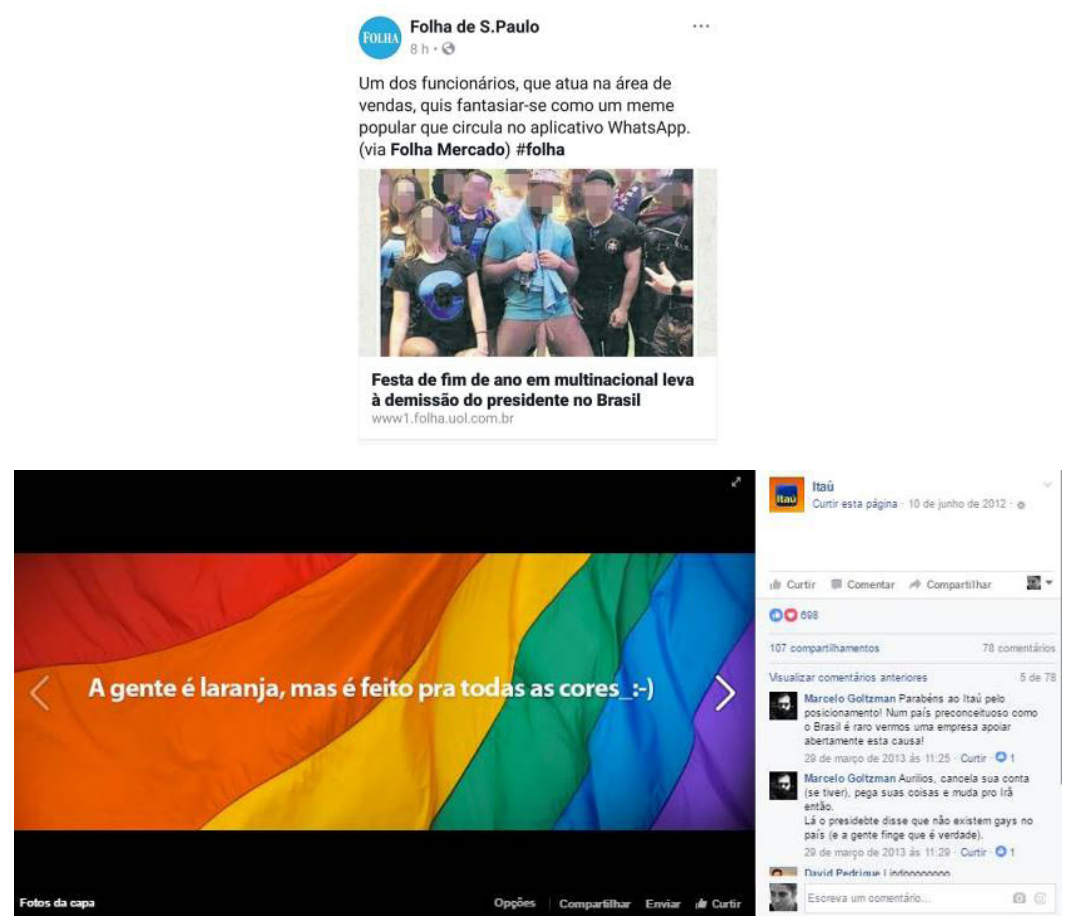

Fonte: Facebook da Folha de S. Paulo e do Banco Itaú (Disponíveis em: http://bit.ly/2nGqpEY e http://bit.ly/2E222wo, respectivamente. Acesso em: 4 fev. 2018)

\section{O endomarketing e a manipulação discursiva das emoções nas empresas}

Em linhas gerais, a noção de endomarketing está relacionada às estratégias e ações típicas de práticas corporativas voltadas especificamente para os funcionários da empresa (endo = movimento para dentro), tais como o aprimoramento da comunicação interna, a realização de eventos e iniciativas de integração, a pesquisa de satisfação ou do clima organizacional, a promoção de palestras motivacionais etc. (BEKIN, 2004). De acordo com o consultor empresarial Saul Faingaus Bekin - que introduziu o termo no Brasil nos anos 1990 - "o endomarketing consiste 
em ações de marketing voltadas ao público interno da empresa, com o intuito de promover entre seus funcionários e departamentos valores destinados a servir o cliente" (BEKIN, 1995, p. 2).

Segundo Brum (2005, p. 34), a prática do endomarketing propõe dar ao funcionário "educação, carinho e atenção", com o fim de torná-lo bem preparado e bem informado para que possa tornar-se também, por seu turno, "uma pessoa criativa e feliz, capaz de surpreender, encantar e entusiasmar o cliente". Para a autora, "hoje não podemos mais falar em uma empresa sem pensar no amor, já que elas são feitas de pessoas, e o amor é algo que permeia todo e qualquer tipo de relacionamento" (BRUM, 2005, p. 27).

Ao avaliar criticamente essa prática empresarial, Andrade (2015, p. 738-739) expõe:

O marketing de experiências pode ser mobilizado para o público interno, promovendo eventos, cenários, comunicações internas, competições corporativas e premiações na forma de experiências, de modo a transmitir regras emocionais e vincular a memória afetiva dos funcionários à empresa. [...] Além disso, no pós-fordismo, não apenas as premiações, mas o próprio trabalho pode ser aproximado do imperativo da "experimentação" próprio ao consumo ao se caracterizar pela variação, inovação, risco e performance emocional. O trabalho não é apresentado no discurso dos managers como algo que demanda apenas sacrifício e aplicação, mas também como algo divertido, emocional e sensorialmente excitante, como uma aventura cheia de riscos e adrenalina, uma experimentação libertadora.

É nesse sentido que o repertório terminológico produzido pelos manuais de endomarketing - tais como os de Brum (2010), Costa (2012), Cerqueira (1994), entre outros - constrói discursivamente mundos afetivos onde os empregados são "colaboradores", "cooperadores", "associados” (NETTO; BRAZ, 2006, p. 217). Com esse controle sobre a retórica das/nas corporações, busca-se camuflar a deterioração das condições laborais da classe operária, a crescente precarização e flexibilização do trabalho, a deficiência e/ou eliminação dos direitos trabalhistas por políticos comprometidos unicamente com os interesses neoliberais do 
capital, entre tantos aspectos que evidenciam a vulnerabilidade dos vínculos empregatícios no Brasil e a sistemática negligência com a qualidade de vida do trabalhador.

Esse controle se dá intrinsecamente através da manipulação dos discursos que circulam no campo empresarial. Como destaca Fairclough (2017, p. 26), o "uso linguístico está assumindo maior importância como meio de produção e controle social no local de trabalho”. Até os anos 1970, com o controle disciplinar fundado preponderantemente no fordismo, a vigilância dos empregados era baseada em uma estruturação hierárquica rígida, na qual se assumia dogmaticamente o primado da ordem e da obediência subserviente. Hoje em dia, o controle sobre o trabalho e a produtividade dos funcionários se apoia em estratégias discursivo-cognitivas muito mais elaboradas.

Para Fairclough (2017, p. 26), “o objetivo é estabelecer novos valores culturais, em que os operários são 'empreendedores', automotivados e [...] 'autodirecionados"'. Em vez do cumprimento servil e resignado de tarefas, estimulam-se a excelência no atendimento, o clima organizacional favorável, a vantagem competitiva, a canalização de esforços estratégicos, a sinergia dos objetivos da empresa e do seu público interno, a experiência de satisfação e realização pessoal no trabalho, o estímulo à meritocracia, o reconhecimento pelo desempenho individual, entre tantos outros clichês tacitamente manipulatórios do jargão corporativo, facilmente encontrados nas cartilhas de endomarketing.

Ao investigar o discurso manipulatório, Charaudeau (2016, p. 68-69) ${ }^{14}$ aponta as suas quatro características fundamentais. Primeiramente, o manipulador não revela seus propósitos reais, camuflando-os sob a forma de um discurso reverso ou assumindo a aparência de estar agindo em benefício do manipulado. É o que ocorre tipicamente com o falacioso argumento de que a recente reforma trabalhista brasileira foi realizada em favor do trabalhador, pois iria gerar mais empregos. Foram retiradas garantias jurídicas históricas dos empregados sob a alegação de

14 Charaudeau (2016) realiza suas análises utilizando como exemplos basicamente discursos políticos. Neste artigo, portanto, parte-se da proposta do autor, adaptando-a aos domínios publicitário e empresarial. 
que isso melhoraria as condições de contratação para as empresas, o que não se concretizou. ${ }^{15}$

Na verdade, o aumento do trabalho temporário e em tempo parcial (contrato intermitente) acaba produzindo maior sentimento de insegurança e instabilidade para os funcionários. Além disso, leis menos rigorosas sobre o tempo de trabalho e a duração dos contratos podem facilitar a exploração da mão de obra - sem a proteção legal de uma jornada mínima - e agravar a distribuição de renda entre empregados e empregadores, em prol dos detentores do capital.

Uma segunda característica do discurso manipulatório ocorre quando o manipulador, com o objetivo de impressionar o manipulado, lança mão de uma posição de legitimidade, que é dada pelo contexto. Isto é, por ser um "dirigente empreendedor", o patrão capitalista ocupa um lugar de prestígio e é socialmente reconhecido como uma autoridade legitimada institucionalmente naquela situação:

O espírito do capitalismo é justamente o conjunto de crenças associadas à ordem capitalista que contribuem para justificar e sustentar essa ordem, legitimando os modos de ação e as disposições coerentes com ela. Essas justificações, sejam elas gerais ou práticas, locais ou globais, expressas em termos de virtude ou em termos de justiça, dão respaldo ao cumprimento de tarefas mais ou menos penosas e, de modo mais geral, à adesão a um estilo de vida, em sentido favorável à ordem capitalista (BOLTANSKI; CHIAPELLO, 2009, p. 42).

Em terceiro lugar, no discurso manipulatório, o manipulador constrói para si uma imagem capaz de paralisar a opinião do manipulado, quer por meio da ameaça, quer por meio da dissimulação. A ameaça corporativa se dá, por exemplo, nos casos de assédio moral dentro do ambiente organizacional, com "chefes durões" submetendo os trabalhadores a situações degradantes e ofensivas, de forma frequente e duradoura, ao longo da sua jornada laboral e no cumprimento de suas funções.

Já a dissimulação nas corporações tem como principal propósito fazer com que os trabalhadores acreditem que possuem uma participação

15 Disponível em: http://bit.ly/2lMPayi. 
significativa e essencial na tomada de decisões da empresa, e que não são meras peças do processo produtivo. Encobre-se o fato de que, no capitalismo neoliberal, o funcionário não é proprietário dos meios de produção e, por isso, a única alternativa que lhe resta é vender sua força de trabalho para garantir sua subsistência. Com a intenção de promover uma valorização cosmética dos seus subordinados, as organizações criam, assim, os chamados Programas de Qualidade de Vida no Trabalho que se destinam, na prática, ao incremento da produtividade e dos lucros (SANT'ANNA; KILIMNIK; MORAES, 2011).

Finalmente, em quarto lugar, Charaudeau (2016) salienta que o manipulador dramatiza o seu discurso de modo a sensibilizar o manipulado, podendo chegar a aterrorizá-lo. Essa última característica do discurso manipulatório será detalhada mais adiante, com base na análise da peça publicitária de uma empresa de endomarketing.

Em síntese, portanto, o discurso manipulatório capitalista almeja, no fim das contas, controlar os interlocutores/trabalhadores ao provocar uma incitação para que eles mudem sua opinião sobre determinado tópico, aderindo ao posicionamento do manipulador/proprietário dos meios de produção. Com esse intuito, esse tipo de discurso amiúde recorre a argumentos de natureza moral ou emocional (coragem, medo, compaixão, motivação, satisfação etc.), sendo frequentemente associado a uma sanção em potencial. Essa sanção pode ser positiva, como é o caso das promessas de obtenção de vantagens futuras, como oferta de remuneração variável, bônus e recompensas, plano de benefícios e saúde etc. Ou pode ser negativa, recorrendo-se à iminência de uma tragédia e impedindo uma reflexão mais ponderada do manipulado, como a ameaça de ser demitido.

Charaudeau (2016) argumenta ainda que um dos recursos de controle mais utilizados pelo discurso manipulatório para a criação de um senso comum é a manipulação pela sedução. No ambiente corporativo, o manipulador fabrica um ethos ou uma autoimagem de credibilidade (quando se apoia no frame da racionalidade) ou de carisma (quando busca um enquadre mais afetivo), visando conquistar os funcionários da 
empresa ao se mostrar um líder nato, um dirigente sério, um gestor competente, um gerente que "arregaça as mangas e bota a mão na massa" etc. São retomadas simbologias sociais clássicas, como a esperança de prosperidade, a expectativa de sucesso por mérito individual, a sensação de júbilo pelo dever cumprido e pela vitória suada etc., sempre sustentadas pela figura do manipulador.

Charaudeau (2016, p. 90) assevera que isso se desenrola a partir da "encenação de um drama" em três atos. A título de ilustração para o presente artigo, podemos observar como essa dramatização se dá no discurso corporativo a partir da análise do anúncio publicitário da agência panamenha de endomarketing Angelcom (Figura 6).

Figura 6 - Os três atos da dramatização na publicidade da Angelcom

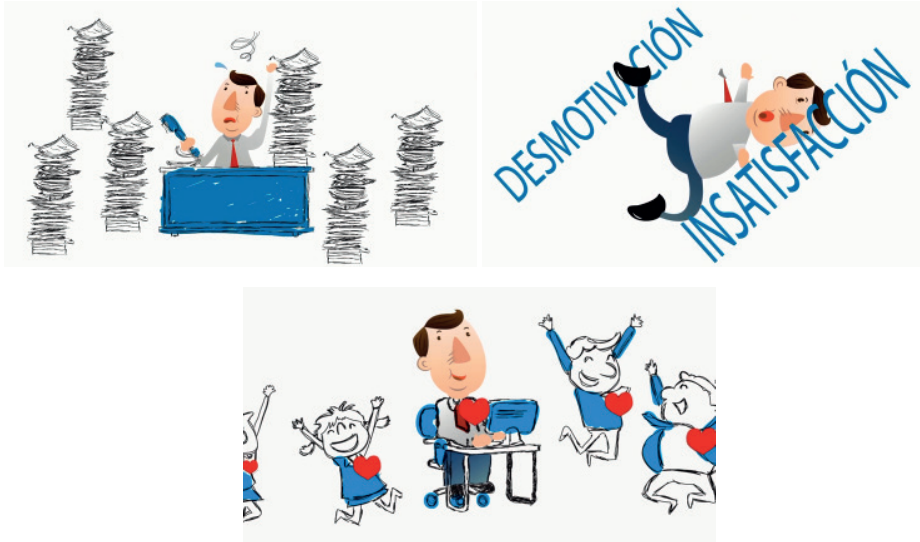

Fonte: YouTube (Disponível em: http://bit.ly/2dZiNuE. Acesso em: 4 fev.2018)

De início, no primeiro ato da dramatização, o discurso manipulatório faz alarde de uma situação de crise, acionando o esquema tipificador de uma desordem social da qual os empregados são vítimas (crise social, crise econômica etc.). No filme publicitário em animação, somos apresentados ao cotidiano do simpático Juan, "um dos muitos panamenhos que, dia a dia, trabalham para levar o sustento a seu lar”. Juan acorda cedo, se arruma rapidamente e depois de duas horas de trânsito em um transporte coletivo, tem que fazer um esforço para ficar agradecido de ao 
menos ter um emprego. Na firma, Juan tem que encarar a indiferença de seus companheiros e o desconforto de seu inóspito espaço de trabalho. O funcionário está frustrado e claramente enfrentando uma crise (Figura 6, à esquerda).

Ato contínuo, conforme Charaudeau (2016), a dramatização do discurso manipulatório tem que identificar uma fonte do mal responsável pela desordem, devendo ser encontrada e denunciada para servir de bode expiatório. A culpa recai sobre o próprio Juan, que passa "todo o expediente pensando quando será a hora de sua saída”. Juan é citado como um exemplo dos "milhares de colaboradores que, com o tempo, diminuem sua produtividade por se sentirem desmotivados e insatisfeitos" (Figura 6, ao centro). O funcionário também é descrito como "sem nenhum sentimento de identidade com seu lugar de trabalho". Subjaz aqui a compreensão de que Juan tem necessariamente que mudar para se adequar ao que a companhia espera dele.

Por fim, como terceiro e último ato da dramatização, surge a solução salvadora, encarnada na imagem de um "salvador da pátria", comprometido em reparar a situação de desordem. A agência de endomarketing anunciante se oferece, enfim, como capaz de gerar um "melhor clima laboral, fomentando o compromisso [...], a cultura da organização e, especialmente, motivando a trabalhar com paixão para que todos remem com o mesmo objetivo: o objetivo da empresa". Para tanto, ao colaborador devem ser vendidos a marca, os valores e a cultura da organização, com o fito de "reforçar o empoderamento e gerar um clima de felicidade laboral” (Figura 6, à direita).

Em outras palavras, não importa, no fundo, que Juan continue tendo que acordar cedo todos os dias, que ele permaneça preso em um ônibus por duas horas antes de chegar ao escritório, que a indiferença de seus colegas não vá necessariamente desaparecer, nem que seu volume de trabalho, prazos apertados e cobranças sejam mantidos. O que importa para que Juan continue no seu emprego - e não sofra a sanção negativa de ser demitido ou de passar por um rebaixamento de função - é que ele basicamente se mostre feliz, realizado e produtivo no trabalho. Se Juan 
não se sente assim, ele mesmo é o principal responsável por ser incapaz de "dar o melhor de si" e de não compartilhar da alma da empresa, por não possuir persistência, motivação e autoconfiança, por não ser proativo nem gerador de valor etc. Pobre Juan...

\section{Considerações finais}

Ao longo do artigo, foi possível observar como a virada afetiva no domínio discursivo organizacional opera com o propósito de produzir subjetividades assujeitadas e corpos dóceis, controlando e delimitando as possibilidades do sentir e do agir, mas fazendo com que o sujeito acredite participar ativamente do processo decisório. No campo publicitário, isso se manifesta pela incessante procura das empresas pela mensuração da resposta emocional do consumidor, tentando compreender como direcionar comportamentos, crenças e desejos para fazê-lo se aproximar afetivamente das marcas. Já no ambiente corporativo, esse fenômeno é percebido nas estratégias de marketing voltadas para o controle das emoções do público interno, tendo como propósito maior camuflar a exploração da força de trabalho pelos proprietários dos meios de produção e promover valores neoliberais, como a competitividade, a individualidade e a acumulação de bens. Ademais, também foi discutido acima como, sob a ótica do capital emocional, a conexão entre esses dois atores - consumidores e trabalhadores - é cada vez mais estreita e intensa.

No case analisado da agência de endomarketing, por exemplo, restou evidenciado que a mensagem da animação publicitária finda por promover a culpabilidade do elo mais frágil do vínculo empregatício: o funcionário. Isto é, em princípio, bastaria que a empresa adotasse as técnicas de endomarketing oferecidas pela Angelcom, para se eximir de quaisquer problemas decorrentes do baixo desempenho do empregado e lhe responsabilizar pessoalmente por seus insucessos na corporação. Ao ser controlado acerca do que, quando e como deve se sentir e/ou se expressar afetivamente, o trabalhador se vê destituído do que lhe caracteriza enquanto ser humano em prol de "muita retórica sobre liberdade 
individual, autonomia, responsabilidade pessoal e as virtudes da privatização, livre-mercado e livre-comércio" (HARVEY, 2011, p. 16).

Cabe, por fim, registrar que nem sempre essa dinâmica neoliberal do capitalismo emocional é aceita de maneira pacífica e inquestionável. Há, sim, focos de resistência e de dissidências, constituídos por sujeitos econômicos que se empenham para conquistar minimamente uma autonomia, em maior ou menor grau, na gestão de suas emoções e subjetividades, fora das grandes corporações. Deliberadamente, eles se propõem a não abrir mão do controle sobre seus sentimentos, não se submetendo à lógica consumista publicitária e aos valores das corporações das quais são clientes ou para as quais trabalham.16

É o caso, por exemplo, de movimentos contra-hegemônicos como o Lowsumerism, o Adbusters Media Foundation e o L'Observatoire Indépendant de la Publicité - que alertam para os malefícios ocasionados pelo capitalismo, pelo consumismo exacerbado e lutam por uma publicidade mais responsável; o Brandalism, o Anti Pub (Résistance à l'Agression Publicitaire) e o The Bubble Project - que promovem ações artísticas de guerrilha nos espaços públicos, com intervenções em outdoors, cartazes e anúncios de rua. São iniciativas coletivas de consumo político que ambicionam tensionar o status quo e questionar as formas institucionalizadas de (re)produção da dominação pelas elites capitalistas e do abuso de poder sobre consumidores e trabalhadores.

\section{Referências}

ANDRADE, D. P. Vigilância e controle dos afetos no trabalho. In: SIMPÓSIO INTERNACIONAL LAVITS, 3., 2015, Rio de Janeiro. Anais... Rio de Janeiro: LAVITS, 2015. p. $726-745$.

BAUMAN, Z. ¿La riqueza de unos pocos nos beneficia a todos? Barcelona: Paidós, 2014. BEKIN, S. F. Conversando sobre endomarketing. São Paulo: Makrons Books, 1995. Endomarketing. São Paulo: Prentice Hall, 2004.

BOLTANSKI, L.; CHIAPELLO, E. O novo espírito do capitalismo. São Paulo: Martins Fontes, 2009.

16 Ver Hollenbeck e Zinkhan (2006). 
BOURDIEU, P. L'essence du néolibéralisme. Le Monde Diplomatique, Paris, p. 3, mar. 1998.

BRUM, A. de M. Endomarketing de A a Z. São Paulo: Integrare Editora, 2010.

Respirando endomarketing. Porto Alegre: L\&PM, 2003.

BRUNO, F. Máquinas de ver, modos de ser. Porto Alegre: Sulina, 2013.

CARRASCOZA, J. A. Estratégias criativas da publicidade. São Paulo: Estação das Letras e Cores, 2014.

CASAQUI, V. A felicidade nos mundos possíveis da publicidade. Comunicação e Consumo: Cápsulas para consumo, n. 18, abr. 2011. Disponível em: http://bit.ly/2EdeybN. Acesso em: 2 ago. 2018.

Abordagem crítica da cultura da inspiração: produção de narrativas e o ideário da sociedade empreendedora. E-Compós, v. 20, n. 2, p. 1-18, maio-ago. 207.

CASTRO, G.G.S. Entretenimento, subjetividade e consumo nas redes digitais. In: BARBOSA, M.; MORAIS, O. (Orgs.). Comunicação em tempo de redes sociais. São Paulo: Intercom, 2013. p. 177-198.

CERQUEIRA, W. Endomarketing. Rio de Janeiro: Qualitymark, 1994.

CHARAUDEAU, P. A conquista da opinião pública. São Paulo: Contexto, 2016.

CLOUGH, P. The affective turn. Durham: Duke University Press, 2007.

COSTA, D. Endomarketing inteligente. Porto Alegre: Dublinense, 2012.

COSTA, S. Romanticism and consumerism in late modernity. Novos estud. - CEBRAP, v. 1, n. se, p. 1-13, 2005.

CURY, A. Gestão da emoção. São Paulo: Saraiva, 2015.

DAMÁSIO, A. R. O erro de Descartes. São Paulo: Companhia das Letras, 1996.

DELEUZE, G. Post scriptum sobre as sociedades de controle. In: Conversações: 1972-1990. Rio de Janeiro: Ed. 34, 1992. p. 219-226.

DOMINGUES, I. Publicidade de controle. Porto Alegre: Sulina, 2016.

ELIAS, N. O processo civilizador. Rio de Janeiro: Jorge Zahar, 1994b.

O processo civilizador. Rio de Janeiro: Jorge Zahar, 1994a.

FAIRCLOUGH, N. Discurso e mudança social. Brasília: Ed. UNB, 2017.

FISCHER, R. M. B. Trabalhar com Foucault. Belo Horizonte: Autêntica, 2012.

FOUCAULT, M. Naissance de la biopolitique. Paris: Gallimard-Seuil, 2004.

Vigiar e punir. Petrópolis: Vozes, 1983.

FRANÇA, V. V. "A felicidade ao seu alcance”. In: FREIRE FILHO, J. (Org.). Ser feliz hoje. Rio de Janeiro: Ed. FGV, 2010.

FREIRE FILHO, J. A felicidade na era de sua reprodutibilidade científica. In: FREIRE FILHO, J. (Org.). Ser feliz hoje. Rio de Janeiro: Ed. FGV, 2010.

HARDT, M. A sociedade mundial de controle. In: ALLIEZ, E. (Org.). Gilles Deleuze. São Paulo: Ed. 34, 2000. p. 357-372.

HARVEY, D. O enigma do capital. São Paulo: Boitempo, 2011.

HOLLENBECK, C. R.; ZINKHAN, G. M. Consumer activism on the internet: the role of anti-brand communities. Advances in Consumer Research, v. 33, p. 479-485, 2006.

ILLOUZ, E. O amor nos tempos do capitalismo. Rio de Janeiro: Zahar, 2011. 
LAZZARATO, M. Créer des mondes. Multitudes, n. 15, v. 1, p. 229-237, 2004.

LEAL, J. Sadia resgata ícones da marca para emocionar em nova campanha. O Povo Online, 5 jul. 2017. Disponível em: http://bit.ly/2s6lId5. Acesso em: 4 fev. 2018.

MACKEY, J. O tipo de capitalista que você quer ser. Azul Magazine, n. 57, p. 88-89, jan. 2018.

MACKEY, J.; SISODIA, R. Capitalismo consciente. São Paulo: HSM, 2013.

NETTO, J. P.; BRAZ, M. Economia política. São Paulo: Cortez, 2006.

POELS, K.; DEWITTE, S. How to capture the heart? Journal of Advertising Research, v. 46, n. 1, p. 18-37, 2006.

SANT'ANNA, A. S.; KILIMNIK, Z. M.; MORAES, L. F. R. Antecedentes, origens e evolução do movimento em torno da qualidade de vida no trabalho. In: SANT'ANNA, A. S.; KILIMNIK. Z. M. (Orgs.). Qualidade de vida no trabalho. Rio de Janeiro. Elsevier, 2011. p. 3-30.

THOMSON, K. Emotional capital. Oxford: Capstone, 1998.

VAZ, P. A vida feliz das vítimas. In: FREIRE FILHO, J. (Org.). Ser feliz hoje. Rio de Janeiro: Ed. FGV, 2010.

\section{Sobre os autores}

Rogério Luiz Covaleski - Realizou estágio pós-doutoral sobre Conteúdo de Marca na Universitat Pompeu Fabra, em Barcelona, Espanha, é Doutor em Comunicação e Semiótica (PUC-SP), Mestre em Comunicação e Linguagens (UTP), Especialista em Propaganda e Marketing (ISPG) e Graduado em Comunicação Social Publicidade e Propaganda (PUC-PR). Atualmente, é Professor Associado na graduação em Publicidade e Propaganda (DCOM/ UFPE) e Professor permanente do Programa de Pós-graduação em Comunicação (PPGCOM/UFPE Universidade Federal de Pernambuco). No presente artigo, o autor participou da concepção do desenho da pesquisa, do desenvolvimento da discussão teórica, da redação do manuscrito e da revisão do texto.

Leonardo Pinheiro Mozdzenski - Doutor em Comunicação pelo Programa de Pós-Graduação em Comunicação da Universidade Federal de Pernambuco (PPGCOM/UFPE) e doutor em Linguística pelo Programa de Pós-Graduação em Letras da mesma instituição (PPGL/UFPE). É bacharel em Economia, licenciado em Letras (Português-Inglês), mestre em Linguística e possui especialização em "Leitura, Compreensão \& Produção Textual”, todos cursados 
520 VEM SER FELIZ

na UFPE. No presente artigo, o autor participou da concepção do desenho da pesquisa, do desenvolvimento da discussão teórica, da redação do manuscrito e da revisão do texto.

Data de submissão: 27/1 1/2019

Data de aceite: 07/08/2020 